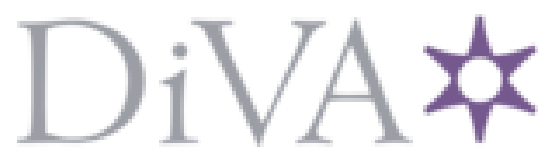

http://www.diva-portal.org

This is the published version of a paper published in Vehicle System Dynamics.

Citation for the original published paper (version of record):

Stensson, A., Larsson, T., Merkt, T., Schuller, J., Williams, R A. et al. (2000)

Industry demands on vehicle development - methods and tools.

Vehicle System Dynamics, 33(Suppl): 202-213

Access to the published version may require subscription.

N.B. When citing this work, cite the original published paper.

Permanent link to this version:

http://urn.kb.se/resolve?urn=urn:nbn:se:bth-11314 


\title{
Industry demands on vehicle development - methods and tools
}

\author{
ANNIKA STENSSON $^{1}$, TOBIAS LARSSON ${ }^{1}$, THOMAS MERKT ${ }^{2}$, \\ JÜRGEN SCHULLER ${ }^{3}$, R.A. WILLIAMS ${ }^{4}$ and LUTZ MAUER ${ }^{5}$
}

\begin{abstract}
SUMMARY
A very important goal of mechatronics in system development is the integration of mechanical, electronic and software subsystems in order to increase functionality, minimise weight, and reduce production costs. In this work, industry demands on methods and tools for mechatronic vehicle development are addressed from the current product development in industry. The development of a mechatronic car door concept and dynamic stability control are used as examples to identify strong and weak parts of the current processes. Railway vehicle development aspects are also discussed. It is shown that a very important aspect for a successful mechatronic design is co-operation in an interdisciplinary design team. In terms of design methodology, the systematic identification of mechatronic potential based on function analysis is a main issue. Computer tools and technology for concept simulation, co-simulation, managing of models with different complexity as well as model exchange are identified as important demands for future effective development of mechatronic vehicles.
\end{abstract}

\section{INTRODUCTION}

Global competition requires the introduction of new products or innovations in the shortest possible time. This 'time to market' requirement is a strong argument for shortening the product development time as much as possible. On the other hand, only a limited budget is available for product development, despite constantly rising product complexity. Consequently, the efficiency of the product development process must be increased, without sacrificing product quality. Those targets can only be achieved by the introduction of a taut project organization and simultaneous engineering strategies in product development, procurement, production, sales, customer service etc., as well as with the early inclusion of suppliers as system providers who are responsible for the development and the function of their components.

Today, vehicle engineers have a great freedom of choices of solution. Alternative machine systems are commonly built from some combination of mechanical, electrical, fluid-power, electro-mechanical and digital computing elements. Examples of such products are systems for anti spinn, stability control, adaptive cruise control, collision and warning systems, variable stiffness and damping systems, engine control and tilting train systems. Thus the designer need

\footnotetext{
${ }^{1}$ Luleå University of Technology, SE-971 87 Luleå, Sweden. ${ }^{2}$ Porsche, Porschstrase, 71287 Weissach, Germany. ${ }^{3}$ BMW AG, 80788 Munchen, Germany. ${ }^{4}$ Jaguar, Whitley, Coventry CV3 4LF, Great Britain. ${ }^{5}$ INTEC GmbH, Münchener Straße 20, 82234 Weßling, Germany.
} 
to weigh up the relative advantage of choosing elements from each class and subsequently aggregating these elements to produce the best possible design. Thus freedom of choice and appropriate mechatronic integration can lead to new and better products, but it introduces an increased complexity. This implies a need for methods and tools which can assist in the various processes involved in realising such products.

As an example, the development automobiles today is characterised by a large increase in functionality, which has been devoted on one hand to the improvement of passive (e.g. airbags) and active (e.g. dynamic stability systems) safety, and on the other hand to the improvement of the driver's and passenger's comfort. For example, when looking at a modern car door it can be recognised that most of the integrated functions are luxury features, see Figure 1.

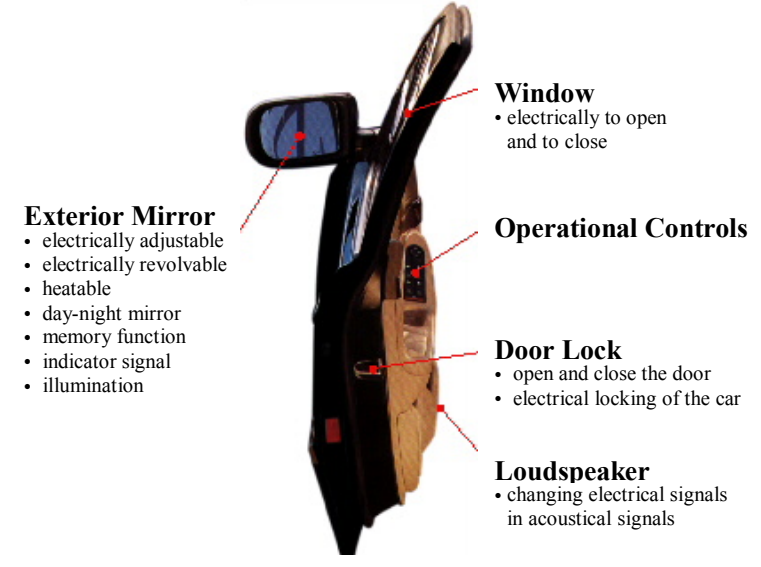

Fig. 1. Functions of a modern car door.

All these subsystems (window lifter, exterior mirror etc.) are separately designed, produced and assembled. This design philosophy creates a number of problems in production costs, weight, and system reliability. In particular, the overall system performance is highly dependent on reliable interfaces between the subsystems. This can be tested only in a very late stage of the development process, which leads to a high uncertainty for the development period.

In this work, demands on methods and tools for effective mechatronic vehicle development are addressed from the current product development process used at some vehicle companies. The development of a mechatronic concept for a car door and dynamic stability control are used as examples to identify strong and weak parts of the current processes. The example with the car door is focusing on design methodology while the example with dynamic stability control is focusing on computer tools and techniques. Railway vehicle development is also discussed. Demands on methods and tools are identified and important aspects such as different set of models at different stages, demands for exchange of information, software tools, working methods and interaction between supplier and company are addressed. 


\section{MECHATRONIC PRODUCT DEVELOPMENT}

There are a variety of methodologies for understanding and enhancing the product development process. Some of these methods are in the form of theories and others are in the form of computer tools. The theories mainly consist of literature and studies establishing a view of how to perform good product development and how to plan the company processes $[1,2]$. The computer tools typically consists of aids for design, analysis, drafting, process planning among others, and are often mentioned as computer aided engineering (CAE) tools [3]. For future development, the vehicle industry will be forced to change their design philosophy for three main reasons:

$\checkmark$ due to high competition, the development time for each vehicle type has to be shortened; the development method will have to change from simultaneous engineering to synergetic engineering (see Figure 2);

$\checkmark$ the strict environmental laws enforce a reduction in weight and fuel consumption;

$\checkmark$ the customer regards these features as standard and is not willing to pay extra money; thus the design process has to be competitive and production costs have to be decreased.

\begin{tabular}{|c|}
\hline Mechanics \\
\hline Electronics \\
\hline Hydraulics \\
\hline Controls \\
\hline Software \\
\hline
\end{tabular}

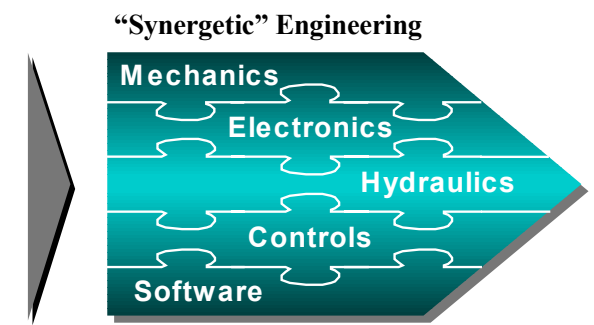

Fig. 2. Synergetic Engineering as one development paradigm of mechatronic design.

Among the first to propose or study the application of electronic control to ground transportation systems such as railways, Maglev-vehicles and automotive systems were $[4,5]$. Their activities have resulted in a number of state-of-the-art articles [610]. The difficulty is not finding areas where mechatronics can be applied, but in locating people familiar enough with the concepts to employ them successfully into the development processes [11]. As a wrap-up it may be said that mechatronics can greatly benefit the vehicle industry.

\section{MECHATRONIC DESIGN METHODOLOGY}

To illustrate different aspects of mechatronic design methodology, the development of a mechatronic car door concept is described. The project was performed as a cooperation between BMW AG and the Institute of Design in Mechanical Engineering at TU München, Germany. 


\subsection{Identification of Mechatronic Potential in the Car Door}

The procedure that has been followed for the purpose of identifying mechatronic potential in this project is shown in Figure 3. It can be seen that this procedure is based on classical design methodology [12], since methods like function analysis and cost analysis of the subsystems are being used. But there are two aspects that are specific to mechatronic design: the consequent team-orientation of engineers from different disciplines and the linking of the system's sub-functions to the list of parts in the connection matrix using physical principles.

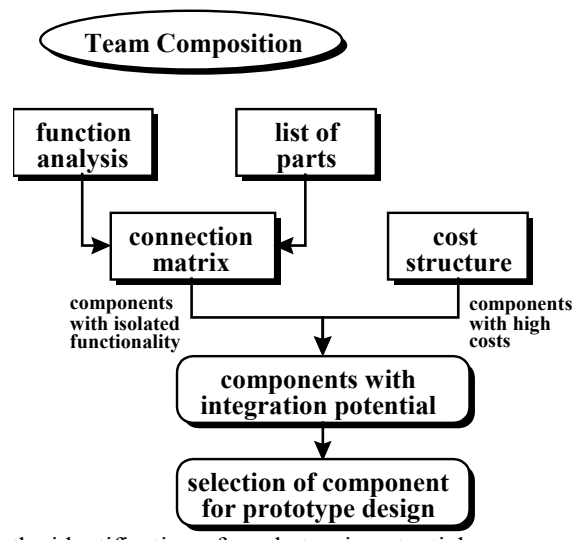

Fig. 3. Procedure for the identification of mechatronic potential.

Mechatronics as understood in this project is a team-oriented approach towards integrative design. From Figure 2 it can be seen, that synergetic engineering requires a close co-operation of engineers from different disciplines. This raises the question of efficient team work and the solution of problems known from studies of group engineering [13]. Here, three problems will be discussed: completeness of the team, monopolies of knowledge, and neutral moderation.

A mechatronic design team should be restricted to a core team (5-8 persons) representing the areas concerning the product. The team should be complete from the beginning of the project while specialists should be involved only temporarily [14]. Integrating a new team member in a later stage of the project often leads to lengthy discussions, because he has to understand all the previous steps and decisions of the design process. Also monopolies of knowledge should be avoided, i.e. no team member should have exclusive knowledge about a subject of interest for the actual design task, since decisions concerning this subject can not be made with a common understanding in the team [14]. It also proved very important to have a neutral moderator in the team. This moderator not only guides the team meetings but also delivers ideas for problem solutions and helps the team to get over frustrating situations during the project. Regarding the team aspect of mechatronic design, industry has to encourage interdisciplinary work. Especially in big companies the team members have to be selected from different departments, thus widening their understanding of the product. This often leads to new and better solutions. 
In order to identify potential for mechatronic design, the existing solution of a product must undergo a function analysis. In this project three analysis techniques have been investigated: function modelling with a hierarchical list, with the IDEF0 formalism, and with structure decomposition. The latter two techniques were software based. Function analysis turned out to be a valuable method to build up a common understanding of the problem, which is a prerequisite for the success of a team-oriented design project. In this project the most useful method for function analysis turned out to be the hierarchical list. Software based function models are more useful when a system like dynamic stability control is modelled, where the system behavior has to be simulated [15].

In order to identify potential for function integration the list of parts has to be linked to the lowest level of functions as found from function analysis [14]. Every link shows the physical principle (mechanical, thermal, optical, acoustical, electrical) of function fulfilment of a component. A simple $\mathrm{ABC}$ analysis uncovers the number of interrelations between the components and functions: the higher the number of interrelations, the higher the integration level of the component. The next step is the identification of the cost structure of the system. Combining the result of functional component analysis with the cost structure, leads to components with potential for mechatronic redesign. Those components with high production costs and isolated functionality should be combined with other parts of the system. In the car door, the following subsystems have been identified: the loom of cables together with the interior door panel, the window lifter, and the exterior mirror. In this project the exterior mirror has been chosen for mechatronic redesign.

\subsection{Design Procedure for Mechatronic Solutions}

For the purpose of integrative design, it is not necessary to invent new technologies, it is more appropriate to apply and combine existing technologies to innovative solutions. In this project three solution finding methods are combined: searching existing solutions, searching solutions with physical principals, and radicalising existing solutions.

The first step was to look for existing solutions showing integrative design, so all examples that could be found by the team members were collected and analysed regarding the applied principles of design. In this project, the examples have been documented and archived in an extendable data base. Every data sheet in the data base contains a picture of the mechatronic component, an explanation of the functionality of the component, the design principle, and a contact person for further information. This data base can be accessed by everybody within the company through the intranet. This is a prerequisite for general acceptance. In addition, the set of examples can be extended continuously. In order to see the usability of a design example for the current task, all the solutions found have to be arranged in a morphological matrix based on the sub-functions of the system [14].

The second step was to search solutions for sub-functions with physical principals [16]. Especially in sensor and actuator technology this method proved to be very helpful for finding new solutions to fulfil sub-functions of the system. For the exterior mirror, this method was applied for the selection of a sensor which measures the position of the mirror glass. The third step was to radicalise 
existing solutions. In a brainstorming session an attempt was made to imagine how subsystems of the car door would look if these technologies were applied to the edge of their potential. The last step in this procedure was to decide which technology had to be used for the mechatronic redesign and prototypical realisation of the exterior mirror. From existing solutions, three useful technologies were identified: leadframe technology, 3D-MID technology (3DMoulded Interconnection Device), and flexible circuit board technology. With the method of preselection (see Figure 4), it was first decided which of the three technologies would be most useful, especially in combination with the electrical bridging of the mirror hinge.

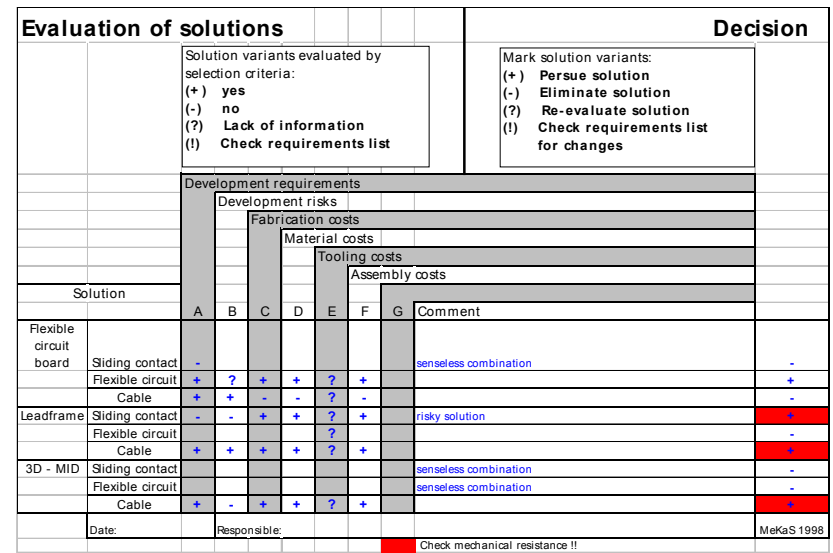

Fig. 4. Method of preselection for the identification of suitable technologies for the design task [14].

Several aspects such as development requirements, risks, and costs were evaluated. Next, the paired comparison as described in [16] was applied to find the best solution for prototypical realisation. The solutions marked with a ' + ' in Figure 4 had to be compared to each other. The result of this decision process was to build a prototype of the exterior mirror in leadframe technology and to bridge the hinge with cables

An important aspect of product development in automobile industry has not been addressed yet: the co-operation of the car manufacturer with suppliers or other external companies. In this project, the university replaced the specialised companies, whereas a system supplier was not involved. Based on the experience of the team members, a scenario has been outlined that eliminates the influence of suppliers during the conceptual phase. In this case, the supplier is only manufacturer of the mechatronic solution that has been conceived by the car manufacturer together with specialised companies, see Figure 5. The reason for this scenario is that in the early development phase, much know-how is built up, and is worth being protected. It has to be stressed that this scenario is probably only applicable for the development of new concepts. For other projects it may be feasible to involve the supplier from the very beginning, especially if know-how is available in this area. In Figure 6 the rate of involvement of car manufacturer, 
suppliers, and specialised companies is shown qualitatively for the conceptual phase of mechatronic design.

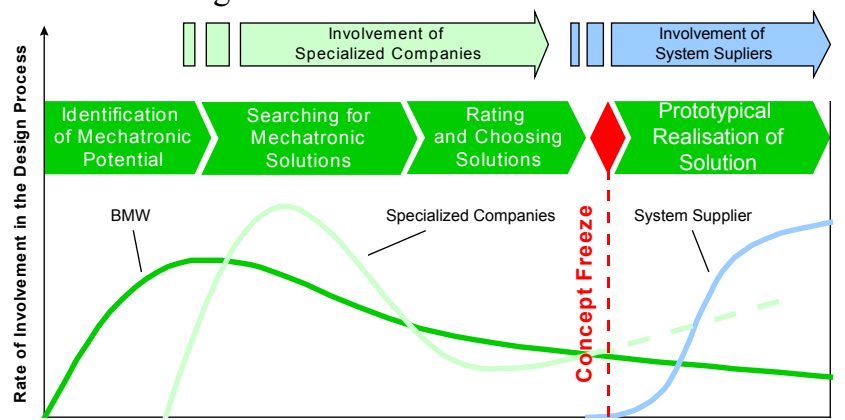

Fig. 5. Involvement of BMW, external companies and system suppliers in the development of mechatronic concepts.

\section{COMPUTER SIMULATION IN MECHATRONIC VEHICLE DESIGN}

High-performance mechatronic systems require that the static and dynamic behaviour is well designed [17]. This means a systematic development, starting with modelling and simulation and using methods for identification and computer aided control system design. Historically large corporations, public bodies and Universities developed their own computer codes to solve specific problems, as there was no alternative. With the evolution of a sophisticated software industry however the automotive industry has developed a preference for commercially available tools. This has the advantage that the same tools are readily available to both OEM and supplier. Commercial software also is invariably developed, and maintained, to a higher level than in house software, as it is not competing for scarce resource which does not directly support the companies core business.

To illustrate different aspects of computer simulation in mechatronic vehicle development, the development of cars and particularly dynamic stability control at Jaguar is described.

\subsection{Automotive Development Process}

In order to design and develop a high quality motor car in the short time scales demanded by the market place, it is essential to use a top down design process which clearly defines the product, it's systems, subsystems and components in a well defined and logical manner. Coupled with advanced CAD and CAE techniques this enables simultaneous development of the vehicle, systems and manufacturing facilities to take place with a minimum number of development vehicles, and a short development phase. A flow diagram of the design and development process used in this project is shown in Figure 6. Note that this is a vehicle development process and, to ensure the smooth running of the vehicle programme, any technology used on the vehicle must fully be developed by the time the system targets have been defined. This ensures that technology 
development is application specific, and that the project is not held to ransom by unproved technology.

The first step in the process is to define the vehicle in terms of cost, weight, performance and market sector. Bench marking own and competitor vehicles take place to ensure that the new product will be competitive at the time of launch. Generic models of the vehicle are used to assess the performance requirements of the vehicle and it's systems. One objective at this point is to identify how much technology can be carried over from previous projects. This includes computer models, as they will have been validated as part of the process.

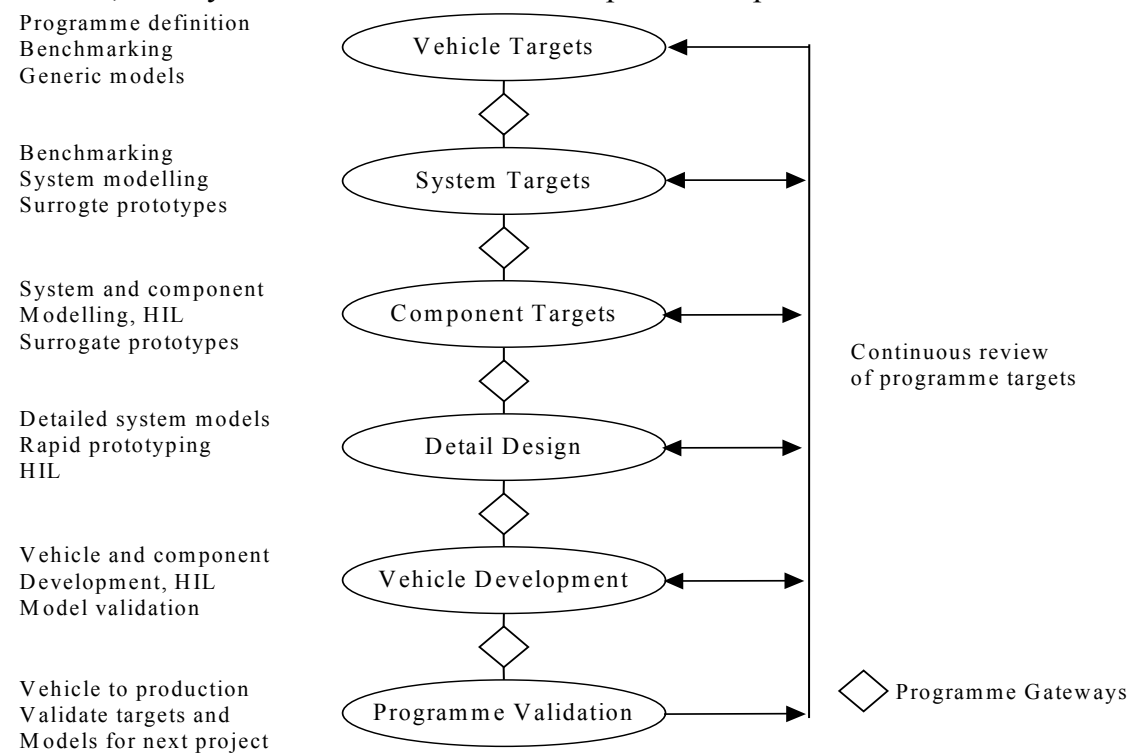

Fig. 6. Design and development process for a mechatronic vehicle.

The next stage in the cycle is to define system level targets to meet the vehicle targets. Benchmarking own and competitor systems take place and modeling moves on to a more detailed phase. As the vehicle architecture has been defined it is possible to generate a vehicle dynamics model using a multi-body code, such as ADAMS or SIMPACK. If the vehicle is based on a carry over platform, validated models will already be available. If the platform is new, tools such as ADAMSPRE, ADAMS CAR and MotionView provide sets of suspension templates to assemble a first pass design. Models of the mechatronic systems should also exist at this point, from the technology development stage, typically with the controllers in Matlab/Simulink or MatrixX and the actuation system in a package such as AMESim or Easy5. Surrogate prototype vehicles and systems are also used to define targets. System targets have to be agreed with the system supplier, and there is a move to exchange models between vehicle manufacturer and supplier to improve the speed and quality of the data produced.

Having set targets for the system the cascade process moves on to setting targets for the components, adding and refining detail to the system models. Hardware in the loop, using for example Dspace, is frequently used to simulate 
systems, which are not available. Again surrogate vehicles and systems are used to provide data. By the time that detailed design starts the CAE models are quite mature, having been an integral part of the target setting process. During this stage there is considerable interaction between $\mathrm{CAE}$ and $\mathrm{CAD}$, which generates the need for a seamless method of interchanging data. An integral part of the design process is the rapid prototyping of control algorithms using Dspace. Models are refined during the vehicle development stage, and used to direct the hardware development programme. Rapid prototyping is used to develop the control algorithms, and hardware in the loop to carry out rig tests of systems and components away from the vehicle.

An important phase of the project occurs after the vehicle is launched, when a review is carried out to asses lessons learned. As with every other stage of the programme, targets are reviewed and the performance assessed against original and revised targets. At this stage of the programme all models used are validated against actual vehicle data so that they can be reused on future projects.

Note that there are gateways between every stage in the programme, see Figure 6. Before the project is allowed to proceed to the next stage all the information required to carry out the next phase of work must be in place, this includes the fidelity of the CAE models.

\subsection{Development of Dynamic Stability Control}

Figure 7 shows the development process for a mechatronic system up to the point where it is ready to be included in a vehicle programme. During this development a range of models will be used with varying levels of sophistication. The process can be described using Dynamic Stability Control (DSC) as an example. In this case the vehicle dynamics are the handling dynamics of the vehicle, the actuators Brakes/ABS and Engine/TCS, as the system provides added function to the ABS and TCS, via an additional set of transducers. At the system concept phase a simple generic-handling model in Matlab or Matrix X, with rudimentary actuator dynamics, is capable of defining function and identifying major system parameters.

Moving on to the prototype design the full system model can be built using, wherever possible, existing models. The models are used to specify the components and control algorithms. The appropriate level of model is important at this stage as large, all inclusive, models will be slow to run, making optimization difficult, if not impossible, within a realistic run time. For instance it would be possible to include engine combustion dynamics and a transmission model within the traction control model.

Prototype development of a mechatronic system is most effectively carried out using a rapid prototyping tool, such as Dspace. The control algorithm can be developed in the same manner as the model, using Simulink, allowing model and hardware development to progress in parallel. In the case of DSC Dspace has also been used to emulate the vehicle dynamics in hardware in the loop (HIL) simulation, allowing system development to take place in a more controlled environment than a moving vehicle. This includes the effects of driving on snow and ice, without having to wait for winter conditions. At the end of this development process it is possible to write the specification for a production system with a high degree of confidence. Note that the models developed during 
the system prototype development stage will be used in the design and development of a production system.
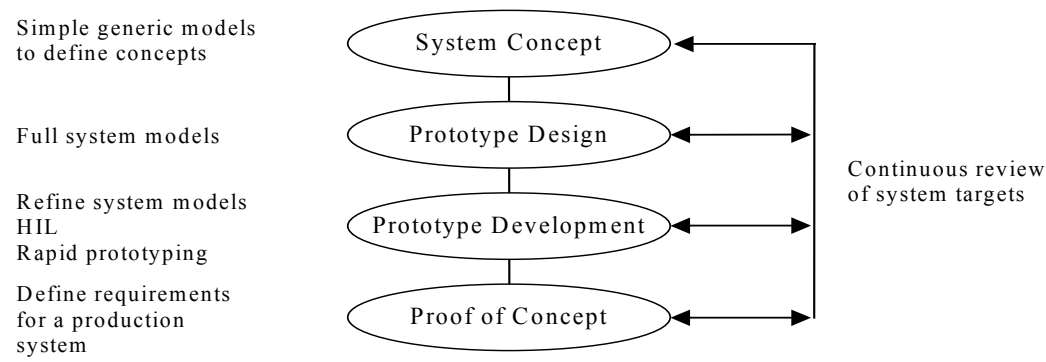

Fig. 7. Mechatronic system development process

\section{RAILWAY VEHICLE DEVELOPMENT}

In contrast to the high number of cars that are manufactured by the automotive industry, the number of wagons produced by railway manufacturers are small. Many orders coming from railway companies contain only a few wagons and there is no possibility for the manufacturer to develop any prototypes of the vehicles for the mean of testing. Each order to the manufacturer of railway vehicles is also related to the special operation conditions for the railway company. One trainset may consist of different types of wagons, such as locomotives and unpowered passenger coaches, powered passenger cars, leading cars, middle cars, trailer cars, bogie vehicles, two axled vehicles and articulated trainsets. There are also different design concepts of bogies to be considered, such as conventional bogies, unpowered and powered, steered axles, steered bogies, actively controlled wheels, wheelsets or bogies, semi-active vertical and/or lateral dampers, active controlled secondary suspension, lateral centering and carbody tilting device.

This illustrates that the variety of the railway systems to be developed is extremely high. Conceptual design and virtual prototyping becomes of even more importance for the manufacturer to bring railway vehicles with an optimized dynamic performance in a faster way to the market. For the conceptual design studies and the virtual prototyping of such variety of railway vehicles, computer tools such as for example SIMPACK is in industrial use [18,19].

Projects for development and delivery of railway vehicles are often large, so that railway manufactures which are competitors on the international market, are working together in particular projects in frame of consortium agreements. Today, most important collaborations between different consorts and/or departments are within:

$\checkmark$ CAD - MBS: conceptual investigations, pre-design;

$\checkmark$ FEA - MBS: theoretical calculation of passenger comfort criteria;

$\checkmark$ CACE - MBS: investigation of active controlled suspension systems, investigation of active controlled driving and braking devices;

$\checkmark$ Dynamic interaction between traction control and running behavior of powered vehicles. 


\section{INDUSTRY DEMANDS}

From the examples described in this work, the following demands on methods and tools for effective development of mechatronic vehicles can be identified.

\section{Working methods:}

$\checkmark$ Mechatronic design is only possible when performed in an interdisciplinary design team.

$\checkmark$ A tool that use function analysis to systematically identify mechatronic potential. The procedure shown in Figure 3 can be taken as guideline for the development of such a tool.

$\checkmark$ A software tool that support the design process. In the car door project, it proved to be very effective to collect examples of mechatronic design in a database.

Modeling requirements:

$\checkmark \quad$ Database oriented administration of component, substructure and full vehicle models together with their status of verification and release.

$\checkmark$ Consistent method for set up of particular simulation models for different use.

$\checkmark$ Consistent method for downsizing the simulation model for other cases of use, like observer model or real time simulation.

$\checkmark$ Use of substructure techniques to change the structure or the complexity of substructures during the stages of conceptual design, final design and parameter optimization. Use of substructure techniques is very important for the handling of large simulation models.

Interfacing requirements:

$\checkmark$ Bi-directional interfaces between the MBS tool for the calculation of the vehicle dynamics and the Computer Aided Design (CAD) Tools, the Finite Element Analysis (FEA) and the Control System Design Software.

$\checkmark$ Open program structure for interfacing with other special software.

$\checkmark$ Open software structure to enable inter-process communication for means of co-simulation with other simulation tools.

Requirements for model exchange:

$\checkmark$ Models of substructures and/or subsystems should be able to transfer as gray boxes to cooperating groups.

$\checkmark \quad$ Transferring of subsystem models should also be able as black boxes without insight, because structures or parameters of the model might be company sensitive.

$\checkmark$ The developer of tools for simulation and design methodologies should be involved in standardization activities and development of common languages, data formats and environments. One effort in that direction is the project "MechaSTEP" [20] which has as a goal to develop a STEP based application data model, as well as a prototype implementation of data exchange processors for selected CAE systems. 


\section{CONCLUSION}

The purpose of this work was to formulate industry demands for future effective development of mechatronic vehicles. A number of demands are identified and illustrated through examples from automobile and railway industries. The demands should also be applicable to the design of other types of vehicles such as combat vehicles and wheel chairs.

\section{ACKNOWLEDGEMENTS}

The support of Joachim Wulf from the Institute of Design in Mechanical Engineering at Technical University of München is greatly acknowledged.

\section{REFERENCES}

1. Ulrich \& Eppinger, Product Design and Development, McGraw-Hill International Editions, Management and Organization Series, 1995.

2. Andreasen, M. M., \& Hein, L., Integrated Product Development, IFS (Publications), Springer Verlag, Berlin/Heidelberg, 1987

3. Mimuro, T., \& Takeuchi, S., CAE in Vehicle Dynamics, International Journal of Computer Applications in Technology, Vol. 2, No. 1, pp. 44-50, 1989.

4. Goodall, R. M., et al., Railway Vehicle Active Suspensions in Theory and Practice, Proceedings of $7^{\text {th }}$ IAVSD Symposium, pp. 301-316, Cambridge, UK 1981

5. Hedrick, J. K., et al., Analysis, Design and Optimization of High Speed Ground Vehicles Using State Variable Techniques, ASME Journal of Dynamic Systems, Measurements and Control, Vol 96, Series G, No 2, pp. 192-203, 1974.

6. Hedrick, J. K., Railway Vehicle Active Suspension - A State of the Art Survey, Vehicle System Dynamics Journal, Vol 10, No 4-5, 1981.

7. Hedrick, J. K. \& Wormley, D. N., Active Suspension - A State of the Art Review, ASME Book No. 100095, AMD-Vol. 15, Mechanics of Transportation Systems, 1975.

8. Goodall, R. M., Kortüm, W., Active Control in Ground Transportation - A Review of the State-ofthe Art and Future Potential, Vehicle System Dynamics, Vol. 12, pp. 225-257, 1983

9. Goodall, R. M., Active Railway Suspensions: Implementation Status and Technological Trends, Vehicle System Dynamics, Vol. 28, pp. 87-117, 1997.

10. Kortüm, W., Goodall, R. M., and Hedrick, J.K., Mechatronics in Ground Transportation Current Trends and Future Possibilities, Annual reviews in Control 22, pp.133-144, 1998.

11. Linsmeier, K. D., ed., Key Technologies in the 21st Century, Scientific American, Vol. 223, No. 3, pp. 74-80, 1995.

12. Pahl, G.; Beitz, W.: Engineering Design. A Systematic Approach. London, Berlin, Heidelberg etc.: Springer Verlag, 1996.

13. Minnemann, S. L.: The Social Construction of a Technical Reality. Empirical Studies of Group Engineering Design Practice. Stanford, PhD thesis, 1997.

14. Wulf, J.: Mechatronic Engineering in Car Body Design. In: Kivikovski, M. (ed.): Proceedings of $2^{\text {nd }}$ International Conference on Machine Automation, Advanced Mechatronics. Tampere 1998, p. 57-68.

15. Busturia, J. M.; Eichberger, A.; Gretzschel, M.; Merkt, E.; Moser, E.; Scholz, C.; Schuller, J.: European Activities and Standardisation Efforts in Mechatronics. Proceedings of $16^{\text {th }}$ IAVSD Symposium on Dynamics of Vehicles on Roads and Tracks, Pretoria, 1999.

16. Ehrlenspiel, K.: Integrierte Produktentwicklung. Methoden für Prozeßorganisation, Produkterstellung und Konstruktion. München, Wien: Hanser Verlag, 1995.

17. Isermann, R., Modelling and Design Methodology for Mechatronic Systems, IEEE/ASME Transaction on Mechatronics, Vol. 1, No. 1, 1996.

18. Stribersky, A., Rulka, W., Netter, H., Haigermoser, A.: Modelling and Simulation of Advanced Rail Vehicles. $8^{\text {th }}$ IFAC Symposium on Transportation Systems '97, Chaniia, Crete, June 16.18. 1997.

19. Jaschinski, A., Schupp, G., Netter, H.: Demonstration of Simulation Potentials in Railway Vehicle System Dynamics through selected Examples. Proceedings World Congress on Railway Research WCRR, Florence, Italy, 16-19 Nov 1997.

20. MechaSTEP. http://www.prostep.de/MechaSTEP.df 